\title{
DESENVOLVIMENTO DE METODOLOGIA DE AVALIAÇÃO DA MOAGEM BASEADA NA LEI DE BOND MODIFICADA NA SAMARCO MINERAÇÃO*
}

\author{
Alexandre Gonçalves Andrade ${ }^{2}$ \\ Renato Luciano de Araújo Menezes ${ }^{3}$ \\ Maycon Athayde 4
}

\section{Resumo}

A Samarco Mineração utiliza combustível sólido para geração de energia térmica nas pelotas de minério de ferro. Este insumo torna possível a redução da utilização de gás natural na etapa de queima nos fornos de endurecimentos e ainda melhora a qualidade física das pelotas. O tamanho das partículas é chave para eficiência do processo e a cominuição destes combustíveis é realizada nas plantas de moagem da empresa, tanto para o antracito quanto para o coque verde de petróleo. Tradicionalmente, um dos principais itens de controle de moabilidade do insumo é o HGI (Hardgrove Grindability Index), que avalia a dureza do combustível sólido no processo de moagem. Porém, este parâmetro não reflete as dificuldades produtivas encontradas nas plantas de moagem da Samarco Mineração. Portanto, foi desenvolvida metodologia através de uma modificação da equação proposta por Bond para avaliação energética de moagem. A lei de Bond tem origem empírica e considera que a energia consumida na cominuição é proporcional ao comprimento das fissuras iniciais que se desencadeiam na quebra das partículas. A metodologia proposta, no presente trabalho, avalia com maior representatividade as dificuldades encontradas na cominuição destes insumos. Ainda, testes em planta piloto de moagem de combustíveis sólidos foram realizados para validação da abordagem.

Palavras-chave: Carvão; Coque; Moagem; HGl.

\section{DEVELOPMENT OF METHODOLOGY OF GRINDING EVALUATION BASED ON MODIFIED BOND EQUATION AT SAMARCO MINERAÇÃO SA}

\section{Abstract}

Samarco Mineração uses solid fuel in order to provide thermal energy in iron ore pellets. This usage reduces natural gas utilization on pellet firing process and improves physical characteristics on final product. Particle size is the main parameter to evaluate the efficiency and reduction of solid fuels in grinding mills, both for coal and pet coke. Traditionally, the main grindability control item is HGI (Hardgrove Grindability Index), which evaluates solid fuel hardness in grinding process. However, this parameter doesn't represent the productive difficulty faced on Samarco's grinding mills. Therefore, it was developed a methodology through modified Bond equation in order to evaluate grinding energy. The empirical Bond law considers a proportion between consumption energy in grinding mills and the initial crack length on broken particles. Proposed methodology evaluates with a higher correlation the difficulty found in these material reduction, further pilot tests were conduced to validate this approach.

Keywords: Coal; Pet coke; Grinding; Hardgrove grindability index.

1 Engenharia metalúrgica e de materiais, engenheiro, engenheiro de processo, departamento de engenharia de processo, Samarco Mineração SA, Anchieta, Espírito Santo, Brasil.

2 Engenharia metalúrgica, engenheiro, engenheiro de processo, departamento de engenharia de produção, Samarco Mineração SA, Anchieta, Espírito Santo, Brasil.

3 Engenharia metalúrgica, mestre, engenheiro de processo, departamento de engenharia de processo, Samarco Mineração SA, Anchieta, Espírito Santo, Brasil.

* Contribuição técnica ao $44^{\circ}$ Seminário de Redução de Minério de Ferro e Matérias-primas, 15ํ Simpósio Brasileiro de Minério de Ferro e $2^{\circ}$ Simpósio Brasileiro de Aglomeração de Minério de Ferro, 15 a 18 de setembro de 2014, Belo Horizonte, MG, Brasil. 


\section{INTRODUÇÃO}

A principal finalidade da adição de carvão é a introdução de energia térmica no processo de endurecimento da pelota, procurando-se assim reduzir o consumo de gás natural, que é um dos insumos mais caros do processo produtivo da Samarco. Além do fator energético, o carvão apresenta influência positiva na qualidade física do produto final - resistência à abrasão e à compressão - desde que dosado adequadamente, garantindo inclusive o aumento da produtividade do processo.

O carvão mineral é classificado como rocha, embora seja de origem vegetal. É uma massa compacta originada da deterioração de matérias vegetais que passaram por vários estágios de decomposição, consequente de ações que provocaram modificações em suas propriedades físicas e químicas. O antracito é a ultima etapa na concepção do carvão mineral e é o material utilizado no processo produtivo da Samarco.

O carvão mineral é composto principalmente de:

- Cinzas - São os resíduos de matéria mineral inorgânica que permanecem na massa da pelota após a queima. Constituem-se, basicamente de sílica e alumina. Quanto maior o teor de cinzas, pior a qualidade do carvão;

- Carbono Fixo - É todo carbono disponível para reagir com o oxigênio e gerar energia durante seu desprendimento na queima da pelota;

- Matérias Voláteis - São as matérias eliminadas, através de gases, durante a queima da pelota.

Quanto maior o teor de carbono fixo, melhor a qualidade do carvão, pois, além de propiciar um aumento na produtividade, reduz consideravelmente o consumo de gás natural nos fornos de pelotização.

O carvão processado na Samarco é importado da África do Sul. O ajuste granulométrico é realizado nas usinas de carvão da Samarco através da moagem do material, buscando a especificação desejada para consumo na pelotização.

O fluxograma de processamento do carvão mineral na Samarco está demonstrado na Figura 1, desde o recebimento até sua adição ao pellet feed [1].

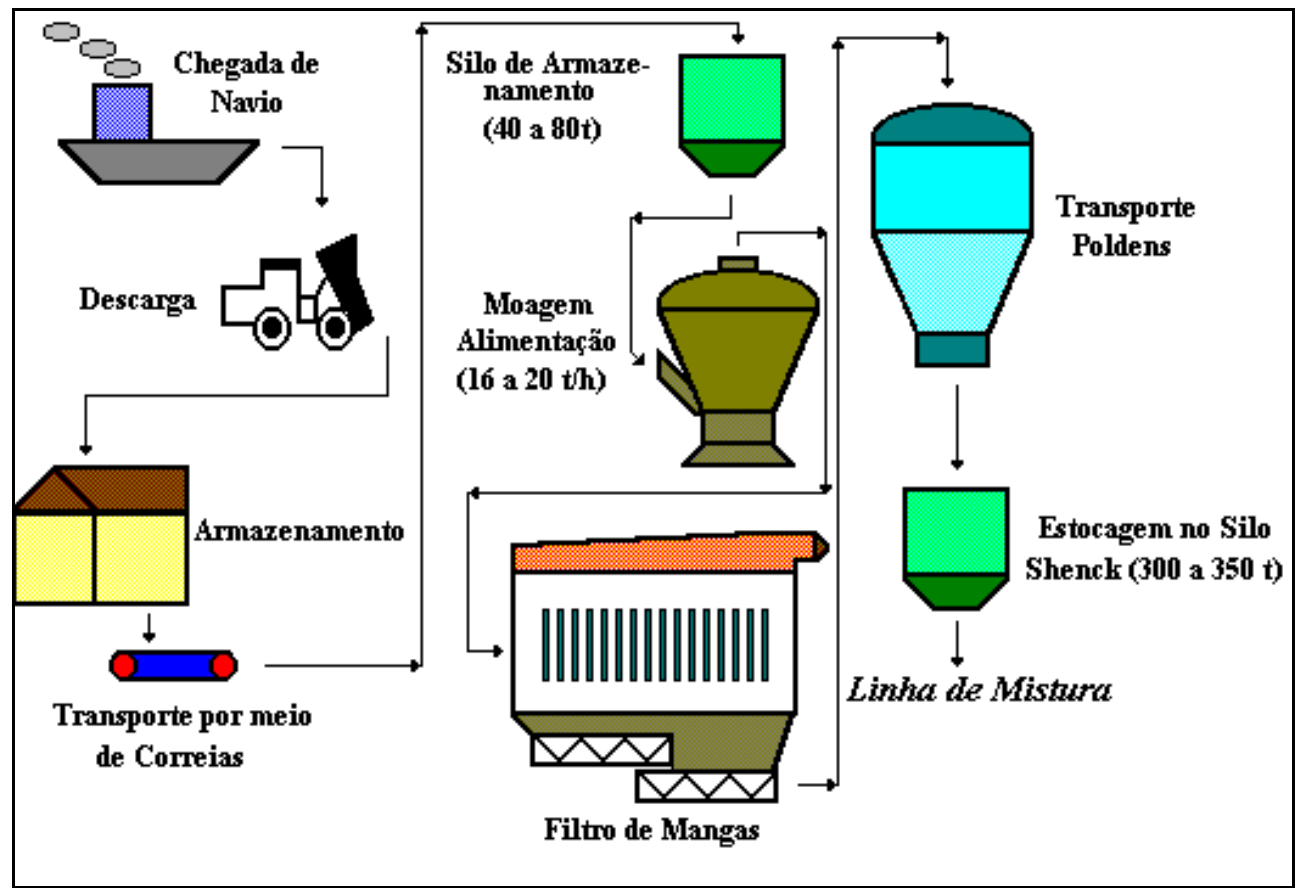

Figura 1: Fluxograma de processamento do carvão na Samarco Mineração SA

\footnotetext{
* Contribuição técnica ao 44온 Seminário de Redução de Minério de Ferro e Matérias-primas, 15은 Simpósio Brasileiro de Minério de Ferro e $2^{\circ}$ Simpósio Brasileiro de Aglomeração de Minério de Ferro, 15 a 18 de setembro de 2014, Belo Horizonte, MG, Brasil.
} 
A Samarco utiliza diversos fornecedores de antracito com características de moagem diferentes. $\mathrm{O}$ teste de $\mathrm{HGl}$ (hardgrove grindability test) é utilizado como um balizador comercial. Porém, foi verificado que este teste não reflete o comportamento do material no moinho de rolos vertical da Samarco Mineração SA.

O teste de $\mathrm{HGl}$ foi desenvolvido em 1930 com objetivo de medir empiricamente a dificuldade na moagem do carvão até o tamanho de partículas necessárias para a completa combustão no forno. Este teste é utilizado como parâmetro em empresas siderúrgicas, produtores de cimentos e indústrias químicas.

O teste utiliza 50 gramas de carvão na granulometria máxima de 1,18 x 0,6 milímetros, que são inseridos em um moinho vertical com 8 bolas metálicas em uma rotação de $50 \mathrm{rpm}$. Após a moagem, somente a parcela menor que 75 microns são utilizados e convertidos na escala HGI [2].

F.C. Bond propôs o uso de um índice conhecido como Wi (work index), que é definido como o trabalho necessário para reduzir uma tonelada curta do material $(907 \mathrm{~kg})$ desde um tamanho inicial considerado infinito até uma granulometria $80 \%$ passante em 100 microns [3].

O presente trabalho desenvolveu um teste de moagem de combustíveis sólidos a partir da lei de Bond modificada, visando entender as interações entre o moinho e o material processado. A metodologia proposta no presente trabalho avalia com maior representatividade a resistência de diferentes materiais na etapa de cominuição, Também foram realizados testes em escala piloto para validação da abordagem.

\section{MATERIAIS E MÉTODOS}

Os testes foram realizados no laboratório da Samarco Mineração. Para a realização dos testes de moagem do carvão, foram inseridos $2 \mathrm{~kg}$ de material num moinho horizontal de bolas com dimensões de $244 \mathrm{~mm}$ de diâmetro interno e $390 \mathrm{~mm}$ de profundidade. O moinho é composto de 38 bolas de $40 \mathrm{~mm}$ e 27 bolas de $50 \mathrm{~mm}$ e é utilizado rotação de $38 \mathrm{rpm}$ durante o teste [4]. A distribuição granulométrica do material é realizada antes do teste de moagem e a cada 30 minutos durante o teste, totalizando 5 medições. A distribuição granulométrica inicial é utilizada para os cálculos de alimentação do moinho, definidos como A80 na fórmula de cálculo energia do moinho proposta por Bond.

Também foram realizadas análises químicas dos materiais testados, através de testes de fluorescência de raios-x para identificação de $\mathrm{SiO} 2, \mathrm{Al} 2 \mathrm{O} 3, \mathrm{CaO}$ e $\mathrm{MgO}$ e cinzas. As análises de carbono e $S$ foram realizadas via analisador infravermelho (Leco), sendo também utilizada a análise química convencional via gravimetria para análise de materiais voláteis e análise do PCI e PCS via calorímetro (Leco).

A análise granulométrica foi realizada da seguinte forma: o carvão recebido para teste foi secado em estufa à $100^{\circ} \mathrm{C}$ por 2 horas. Em seguida, o material passou pelas peneiras de $30,25,19,16,12,5,9,5,6,3,2,1$ e 0,5 milímetros. O material retido em cada peneira foi contabilizado. Após a moagem, a análise granulométrica foi determinada em via úmida e utilizada as peneiras de 100, 200 e 325 mesh (método Tyler).

Para realização do teste e levantamento de dados comparativos, foram utilizadas amostras de antracito e coque visando avaliar o índice de moabilidade dos materiais. A metodologia utiliza uma modificação da lei de Bond para avaliação da energia de moagem necessária na cominuição dos combustíveis sólidos, que é apresentada na equação 1 .

\footnotetext{
* Contribuição técnica ao $44^{\circ}$ Seminário de Redução de Minério de Ferro e Matérias-primas, 15ํ Simpósio Brasileiro de Minério de Ferro e $2^{\circ}$ Simpósio Brasileiro de Aglomeração de Minério de Ferro, 15 a 18 de setembro de 2014, Belo Horizonte, MG, Brasil.
} 
Onde:

$$
W=(10 W i)\left(\frac{1}{\sqrt{D 2}}-\frac{1}{\sqrt{D 1}}\right)
$$

- D1 e D2: diâmetros médios de entrada e saída do moinho e são medidos em $\mathrm{cm}$;

- wi ou work index: intrínseco ao material a ser cominuído e é medido em kwh/t;

- W: energia necessária para moer 1 tonelada do minério e é medido em kwh;

A partir da equação original de Bond e considerando que para a moagem a seco a energia consumida é $33,4 \%$ maior que para a moagem a úmido, a fórmula foi adequada para a equação (2):

$$
\left(\frac{0,134 W}{W i}\right)=\left(\frac{1}{\sqrt{D 2}}-\frac{1}{\sqrt{D 1}}\right)
$$

Vale ressaltar que a lei de Bond é válida para moinhos de bolas. Porém, os moinhos de carvão da Samarco são verticais. Neste caso os testes são realizados em moinho de bolas piloto e os resultados refletem o comportamento do carvão no moinho vertical.

\section{RESULTADOS E DISCUSSÃO}

Foram testadas quatro amostras de diferentes materiais e os resultados serão descritos a seguir. A distribuição granulométrica na entrada e saída do moinho é apresentada na Tabela 1 e Tabela 2.

\begin{tabular}{|c|c|c|c|c|}
\hline $\begin{array}{c}\% \text { retido nas } \\
\text { peneiras (mesh) }\end{array}$ & Padrão & 1 & 2 & 3 \\
\hline 30000 & 13,7 & 4,9 & 24,1 & 2,5 \\
\hline 25000 & 11,2 & 2,2 & 4,3 & 0 \\
\hline 19000 & 7,6 & 4,8 & 4,1 & 2,4 \\
\hline 16000 & 2,1 & 3,9 & 1,7 & 2,5 \\
\hline 12500 & 3,3 & 7 & 3,4 & 3,1 \\
\hline 9500 & 6,6 & 7,6 & 3,3 & 3,8 \\
\hline 6300 & 10,8 & 8,7 & 5,5 & 2,4 \\
\hline 2000 & 22,1 & 29 & 19,5 & 48,7 \\
\hline 1000 & 8,5 & 23,1 & 24,6 & 23,6 \\
\hline 500 & 6,6 & 3,8 & 7,8 & 3,4 \\
\hline & 7,5 & 5 & 1,7 & 7,6 \\
\hline
\end{tabular}

Tabela 1: Distribuição granulométrica dos materiais padrão, 1, 2 e 3 na alimentação do moinho.

* Contribuição técnica ao 44 Seminário de Redução de Minério de Ferro e Matérias-primas, 15은 Simpósio Brasileiro de Minério de Ferro e 20 Simpósio Brasileiro de Aglomeração de Minério de Ferro, 15 a 18 de setembro de 2014, Belo Horizonte, MG, Brasil. 
Tabela 2: Distribuição granulométrica dos materiais padrão, 1, 2 e 3 após moagem.

\begin{tabular}{|l|r|r|r|r|}
\hline \multicolumn{5}{|c|}{ Padrão } \\
\hline Malha/Tempo & 30 min & 60 min & 90 min & 120 min \\
\hline$+100 \#$ & 17 & 2 & 0,8 & 0,6 \\
\hline$-100 \#+200 \#$ & 26,3 & 15,5 & 7,8 & 4,4 \\
\hline$-200 \#+325 \#$ & 13,5 & 18,5 & 16,1 & 13,3 \\
\hline$-325 \#$ & 43,2 & 64 & 75,5 & 81,8 \\
\hline \multicolumn{5}{|c|}{1} \\
\hline$+100 \#$ & 20,5 & 7,5 & 6,3 & 5,9 \\
\hline$-100 \#+200 \#$ & 27 & 22,5 & 16,5 & 13,8 \\
\hline$-200 \#+325 \#$ & 13 & 16,4 & 14,2 & 13,8 \\
\hline$-325 \#$ & 39,5 & 53,7 & 63,2 & 66,6 \\
\hline \multicolumn{5}{|c|}{2} \\
\hline$+100 \#$ & 10 & 7,7 & 7,5 & 7,4 \\
\hline$-100 \#+200 \#$ & 24,5 & 17,7 & 16,7 & 15,5 \\
\hline$-200 \#+325 \#$ & 14,2 & 14,1 & 12,3 & 11,5 \\
\hline$-325 \#$ & 51,3 & 60,6 & 63,6 & 65,6 \\
\hline \multicolumn{5}{|c|}{3} \\
\hline$+100 \#$ & 17,5 & 4 & 3 & 2,5 \\
\hline$-100 \#+200 \#$ & 25,5 & 23 & 17 & 13 \\
\hline$-200 \#+325 \#$ & 12,5 & 16,5 & 16,3 & 16 \\
\hline$-325 \#$ & 44,5 & 56,5 & 63,7 & 68,5 \\
\hline
\end{tabular}

A Figura 2 apresenta o resultado da moagem dos combustíveis sólidos descritos anteriormente. Os resultados mostram que 0 antracito padrão utilizado nas operações da Samarco demanda maior gasto energético para ser cominuído do que os materiais 1, 2 e 3 . Sendo assim, pode-se concluir que ele apresenta menor moabilidade.

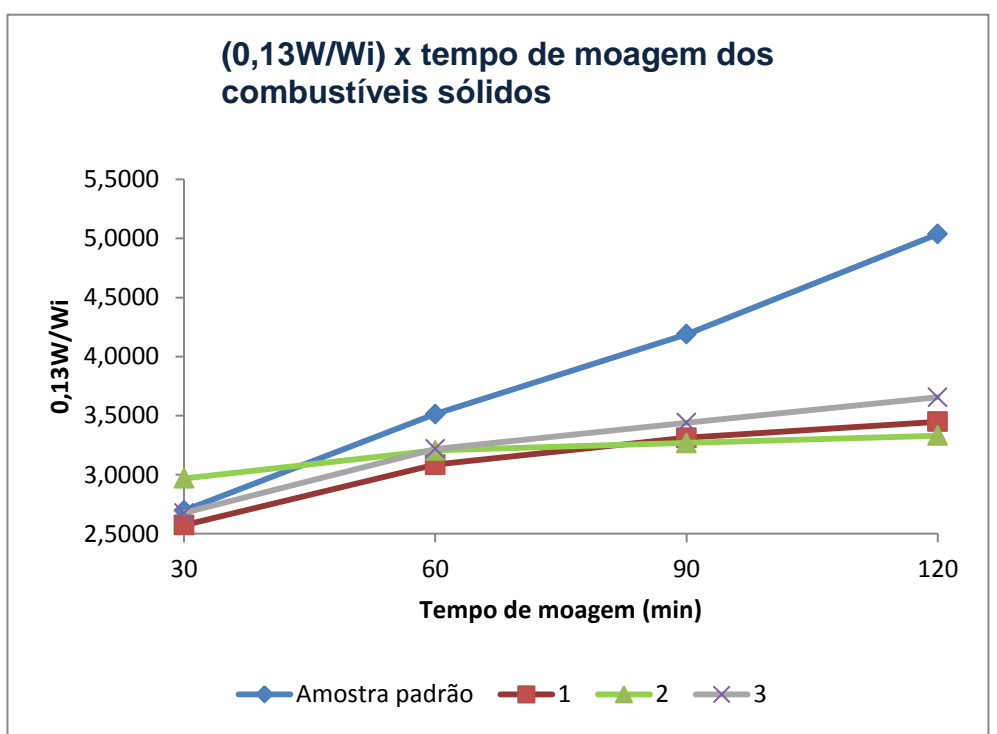

Figura 2: Curva de moabilidade da amostra padrão, amostra 1, 2 e 3

Buscando entender a influência do HGI na produtividade dos moinhos de carvão da Samarco, foram realizados testes com carvões de mesmo HGI de dois fornecedores distintos.

* Contribuição técnica ao 44 Seminário de Redução de Minério de Ferro e Matérias-primas, $15^{\circ}$ Simpósio Brasileiro de Minério de Ferro e $2^{\circ}$ Simpósio Brasileiro de Aglomeração de Minério de Ferro, 15 a 18 de setembro de 2014, Belo Horizonte, MG, Brasil. 
Uma carga apresentou grande dificuldade de moagem nos moinhos industriais da Samarco, reduzindo a produtividade das plantas. Os resultados são apresentados na Figura 3.

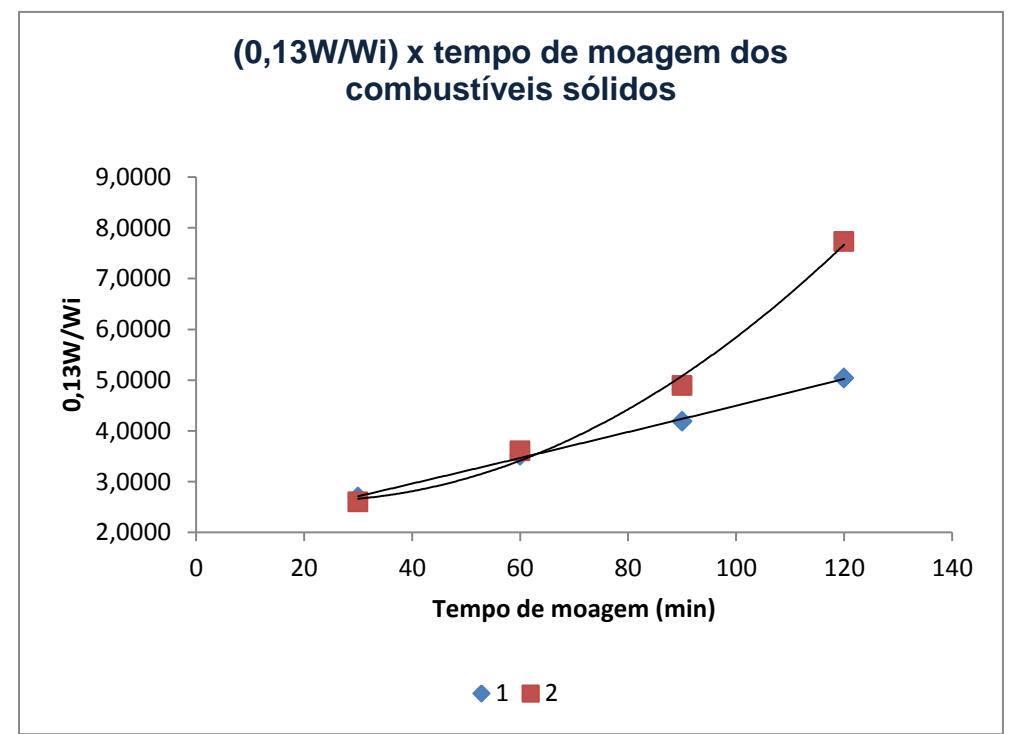

Figura 3: Curva de moabilidade de duas amostras de carvão recebidos na Samarco

Pela análise da Figura 3, nota-se que o carvão com maior dificuldade de moagem resultou em um maior gasto energético de cominuição.

Os resultados de produtividade da planta de carvão 01 são apresentados na Figura 4. O período 1 da figura representa o material 01 e o período 2 representa $o$ material 02.

Torna-se nítida a queda de produtividade da planta com a utilização do material 02. Os dados aqui apresentados são dados industriais reais de uma planta de moagem de carvão da Samarco Mineração. Os mesmos resultados também foram encontrados nas demais plantas de moagem de carvão da empresa.

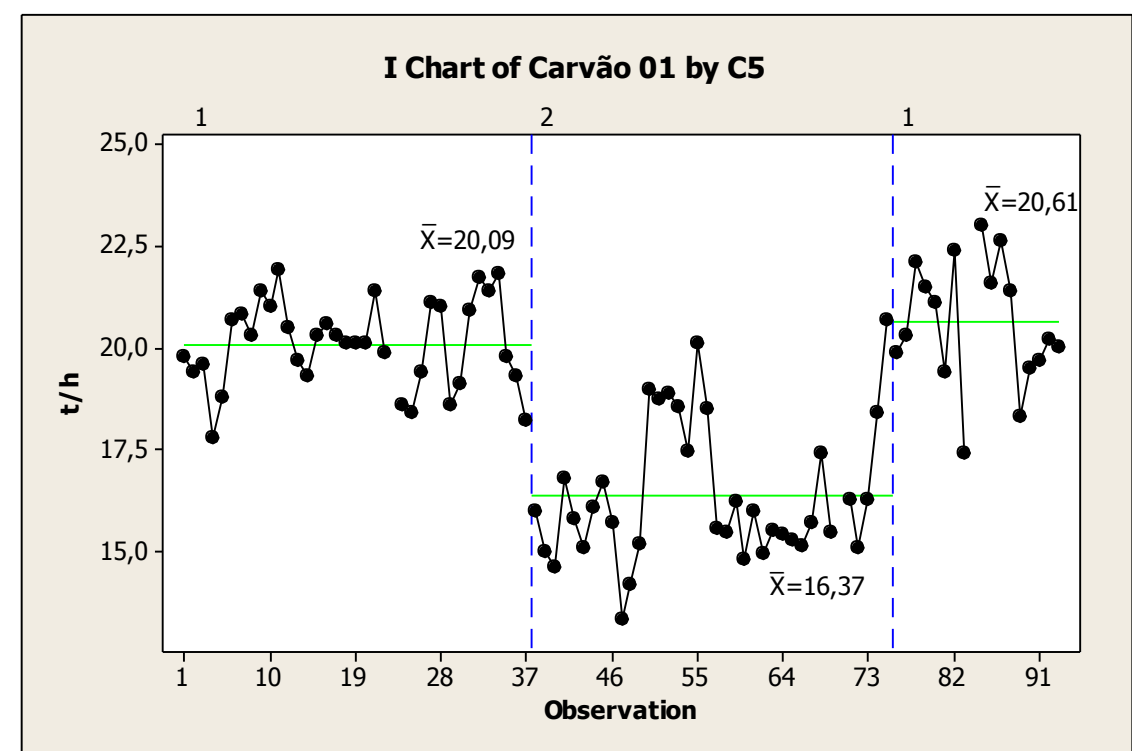

Figura 4: Produtividade da planta de carvão 01.

* Contribuição técnica ao 44 Seminário de Redução de Minério de Ferro e Matérias-primas, 15은 Simpósio Brasileiro de Minério de Ferro e $2^{\circ}$ Simpósio Brasileiro de Aglomeração de Minério de Ferro, 15 a 18 de setembro de 2014, Belo Horizonte, MG, Brasil. 
A Tabela 3 mostra a análise química dos materiais 01 e 02 . A análise do material 02 foi dividida em faixas granulométricas, com objetivo de verificar diferenças na composição química que expliquem a maior resistência à moagem deste carvão nos moinhos verticais da Samarco.

Tabela 3: Análise química do carvão no segundo teste.

\begin{tabular}{|c|c|c|c|c|}
\hline \multicolumn{5}{|c|}{ ESTUDO: Teste de moagem do carvão } \\
\hline DESCRIÇÃO & $\begin{array}{l}\text { Carvão Recebido composição } \\
\text { conforme o padrão }\end{array}$ & $\begin{array}{c}-30,0 \mathrm{~mm}+16,0 \mathrm{~mm} \\
\text { Carvão Recebido }\end{array}$ & $\begin{array}{l}-16 \mathrm{~mm}+0,5 \mathrm{~mm} \\
\text { Carvão Recebido }\end{array}$ & $\begin{array}{l}\quad-0.5 \mathrm{~mm} \\
\text { Carvão Recebido }\end{array}$ \\
\hline DATA & $18 / 01 / 2014$ & $21 / 01 / 2014$ & $21 / 01 / 2014$ & 21/01/2014 \\
\hline \multicolumn{5}{|c|}{ ANÁLISE QUÍMICA } \\
\hline $\mathrm{FeT}(\%)$ & 4,06 & 0,53 & 2,83 & 3,99 \\
\hline $\mathrm{SiO}_{2}(\%)$ & 49,86 & 54,60 & 54,80 & 51,06 \\
\hline $\mathrm{Al}_{2} \mathrm{O}_{3}(\%)$ & 26,29 & 34,07 & 26,36 & 29,64 \\
\hline $\mathrm{CaO}(\%)$ & 1,89 & 0,72 & 2,44 & 2,09 \\
\hline $\mathrm{MgO}(\%)$ & 0,51 & 1,00 & 1,29 & 0,61 \\
\hline $\mathbf{S}(\%)$ & 0,90 & 1,199 & 0,781 & 0,616 \\
\hline Carbono Fixo (\%) & 77,10 & 72,33 & 69,3 & 74,07 \\
\hline Matérias Voláteis (\%) & 6,79 & 12,19 & 7,67 & 9,92 \\
\hline Cinzas (\%) & 16,2 & 15,48 & 23,03 & 16,01 \\
\hline PODER CALORÍFICO (cal/g) & 6623 & 6906 & 6390 & 6378 \\
\hline
\end{tabular}

As principais características observadas na análise química dos materiais com diferentes granulometrias foram o menor teor de ferro presente nos grandes blocos de carvão, assim como maior teor de sílica e materiais voláteis, conforme pode ser observado na Figura 5. No entanto, estas diferenças não explicam a maior resistência à moagem da amostra 02 .
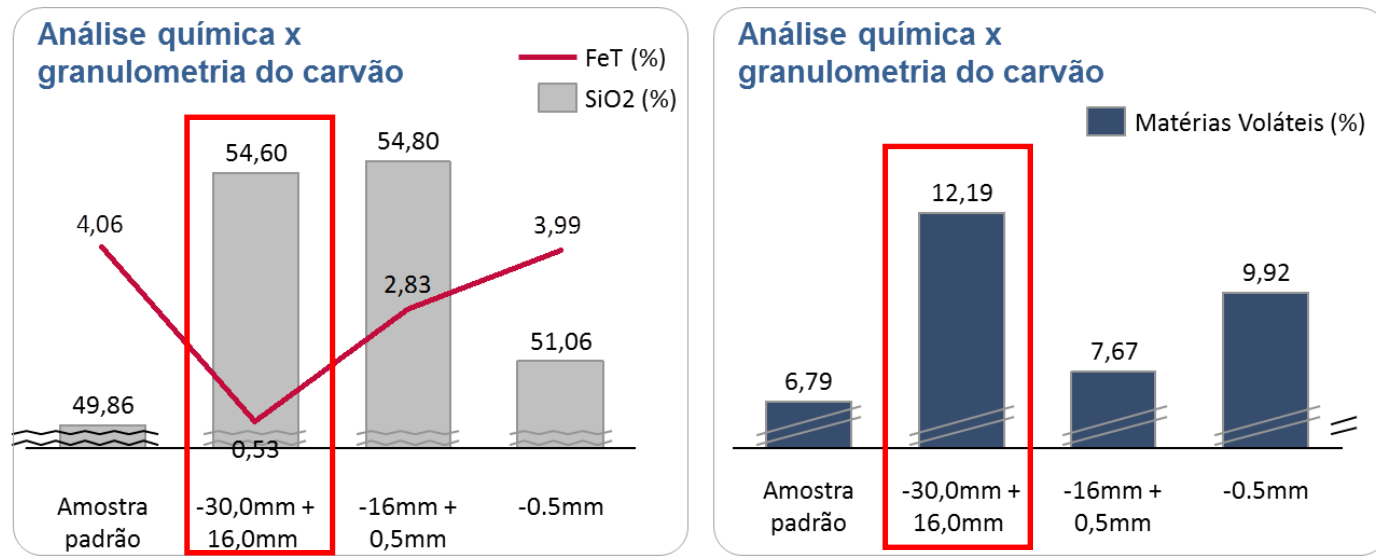

Figura 5: Análise química de 03 grupos de materiais - Grandes blocos, granulometria média e materiais finos.

Também foi realizado relatório fotográfico a cada 30 minutos de teste para a avaliação do aspecto do carvão que apresentou maior resistência à moagem.

A Figura 6 mostra o aspecto final do carvão no moinho piloto. Percebe-se que mesmo após 120 minutos de moagem, a amostra apresenta parcelas de material não cominuído que não foi detectado pelo teste convencional de HGl.

\footnotetext{
* Contribuição técnica ao 44ํ Seminário de Redução de Minério de Ferro e Matérias-primas, 15ํ Simpósio Brasileiro de Minério de Ferro e $2^{\circ}$ Simpósio Brasileiro de Aglomeração de Minério de Ferro, 15 a 18 de setembro de 2014, Belo Horizonte, MG, Brasil.
} 

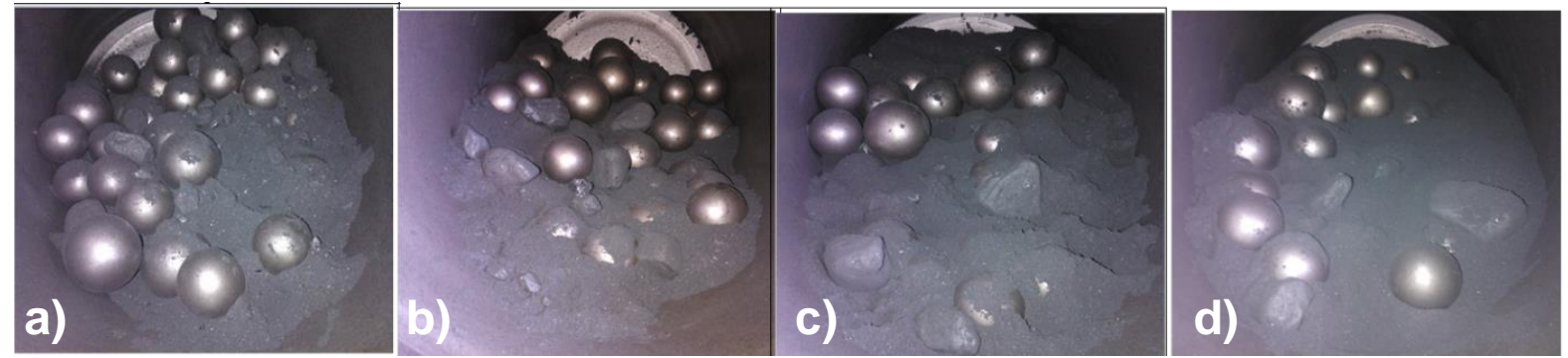

Figura 6: Relatório fotográfico do teste de moagem do carvão que apresentou maior resistência nos moinhos horizontais da Samarco Mineração SA. a) 30 minutos de teste; b) 60 minutos de teste; c) 90 minutos de teste; d) 120 minutos de teste.

A Figura 7 apresenta uma análise microscópica dos carvões submetidos ao teste. A análise da amostra 01 foi realizada antes da moagem, pois todos os blocos foram cominuídos. Já a amostra 02 refere-se a blocos não cominuídos após moagem. Percebem-se grandes diferenças na microestrutura dos dois carvões com HGl semelhantes.
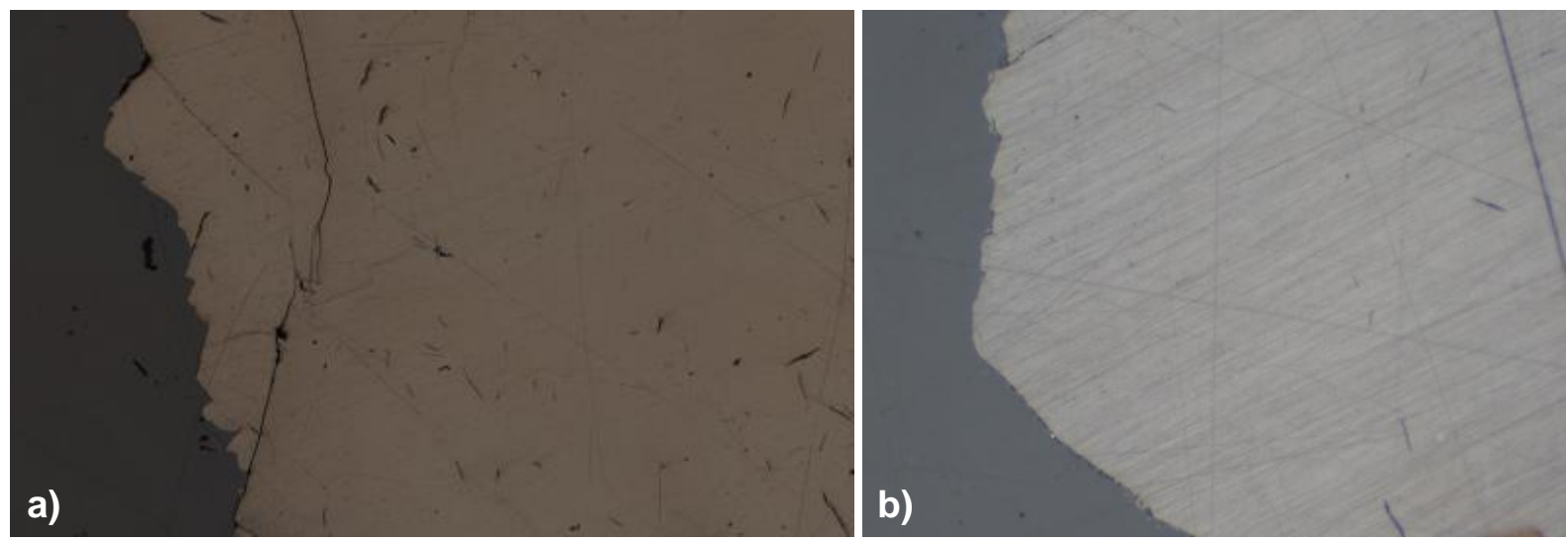

Amostra 1 - a) Ampliação de 50x e b) Ampliação de 500x
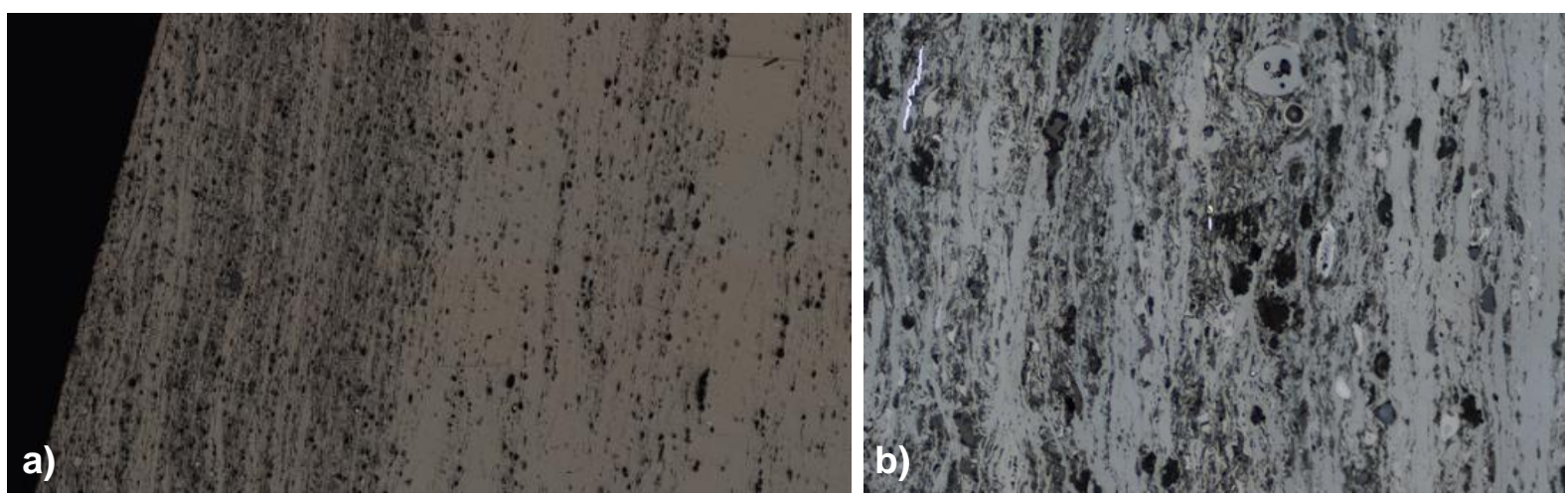

Amostra 2 - a) Ampliação de 50x e b) Ampliação de 500x

Figura 7: Microscopia das amostras de carvão.

\section{CONCLUSÃO}

Conclui-se que a curva de Bond modificada fornece uma melhor previsão do comportamento dos materiais nos moinhos de rolos verticais da Samarco Mineração do que o teste de $\mathrm{HGl}$.

Sendo assim, o HGI se revela uma variável importante somente como parâmetro comercial para compra do insumo.

* Contribuição técnica ao 44ํㅗㄴ Seminário de Redução de Minério de Ferro e Matérias-primas, 15ํ Simpósio Brasileiro de Minério de Ferro e $2^{\circ}$ Simpósio Brasileiro de Aglomeração de Minério de Ferro, 15 a 18 de setembro de 2014, Belo Horizonte, MG, Brasil. 


\section{Agradecimentos}

Agradecemos a todos os envolvidos no trabalho, em especial aos colaboradores dos departamentos de engenharia de processo e de produção da Samarco Mineração em Ponta Ubu.

\section{REFERÊNCIAS}

1 Samarco Mineração SA. Manual Integrado da Gerência de Produção de Ubu. 2013. Revisão 01: 34-38.

2 Acarp - The Australian coal industry's research program. Hardgrove Grindability Index. 2008; 2-3.

3 Luz AB, Sampaio JÁ, Almeida França, Silvia CA. Tratamento de minérios. 5 a Edição. CETEM, 2010; 150.

4 Samarco Mineração SA. Procedimento para moagem em moinho de bolas piloto. 2013:1-2. 